\title{
Supramolecular Chemistry at the Single-Molecule
} Level**

\author{
Rainer Eckel, Robert Ros, Björn Decker, \\ Jochen Mattay, ${ }^{*}$ and Dario Anselmetti*
}

In supramolecular chemistry ${ }^{[1]}$ synthetically designed organic constituents interact noncovalently, in a directed and specific way to form host-guest complexes of higher complexity. The ability to tailor the molecular interplay with respect of chemical design, specificity, and molecular switching opens up the development of new molecular materials for artificial molecular recognition, molecular organization, and selfassembly. We have used mechanical single-molecule force spectroscopy to investigate the binding of individual resorc[4]arene-ligand host-guest complexes. By using diluted samples of the host and guest molecules that are modified with a long linker which is attached to an atomic force microscope (AFM) tip, we were able to prevent multiple binding and to observe single host-guest unbinding events in a supramolecular system for the first time. The molecular binding forces, their dependence on external loading rates, the rate of dissociation, and the molecular cavity length directly relate to the molecular properties of the supramolecular species and are consistent with an activated decay of a metastable bound state, a finding already established for biological receptor-ligand complexes. This result allows new insights into the mechanisms, kinetics, and thermodynamics of intermolecular association in chemistry and biology, and opens new possibilities in the investigation, design, and development of synthetic receptor systems.

Calixarenes are model receptor systems providing synthetic receptor cavities for the inclusion of small cationic guests, such as alkali-metal or ammonium ions..$^{[2-5]}$ Organic cations, such as ammonium ions, play a significant role in molecular recognition processes in nature (e.g. in protein side chains). Calix $[n]$ arenes, generally, are a class of macrocyclic compounds formed by the base-catalyzed condensation of $n$ phenol derivatives and formaldehyde. ${ }^{[2,3]}$ The resorc[4]arenes ${ }^{[6,7]}$ considered herein are calixarenes formed from four

[*] Dipl.-Chem. R. Eckel, Priv.-Doz. Dr. R. Ros, Prof. Dr. D. Anselmetti Experimental Biophysics and Applied Nanoscience Bielefeld University

Universitätsstrasse 25, 33615 Bielefeld (Germany)

Fax: (+ 49) 521-106-2959

E-mail: dario.anselmetti@physik.uni-bielefeld.de

Dipl.-Chem. B. Decker, Prof. Dr. J. Mattay

Organic Chemistry

Bielefeld University

Universitätsstrasse 25, 33615 Bielefeld (Germany)

Fax: (+49) 521-106-6417

E-mail: mattay@uni-bielefeld.de

[***] Financial support from the Deutsche Forschungsgemeinschaft (SFB 613) is gratefully acknowledged.

(2) Supporting information for this article is available on the WWW under http://www.angewandte.org or from the author. 
resorcinol building blocks linked by methine groups. This structure leaves degrees of freedom for rotation around the methine $\mathrm{C}-\mathrm{C}$ bonds, which results in five discernible conformations: crown $\left(C_{4 v}\right)$, boat $\left(C_{2 v}\right)$, chair $\left(C_{2 h}\right)$, diamond $\left(C_{s}\right)$, and saddle $\left(D_{2 d}\right)$. A means to constrain this conformational flexibility in resorc[4]arenes is to link the hydroxy groups at the upper rim of the molecule, to form ether bridges. In this way, the molecule is fixed in the crown conformation, a socalled cavitand ${ }^{[8]}$ and the rigid cavity of this host serves as a template for the inclusion of small guest ions. The binding of cations to the resorc[4]arene cavitand is facilitated by iondipole interactions, although hydrogen bonds and cation$\pi$ interactions between the positive charge of the ion and the cavitand with the aromatic rings also have considerable influence. ${ }^{[9]}$ The specificity of the binding is governed by the steric complementarity of the host and guest: only cations small enough to fit into the tailored cavity are recognized by the resorc[4]arene cavitand receptor. In our experiments the 2,8,14,20-tetra-(10-(decylthio)decyl) cavitand, which has a calculated cavity width of $0.7 \mathrm{~nm}$, serves as a host and its specific recognition of ammonium ions and ammonium-ion derivatives is tested (Figure 1). ${ }^{[9]}$
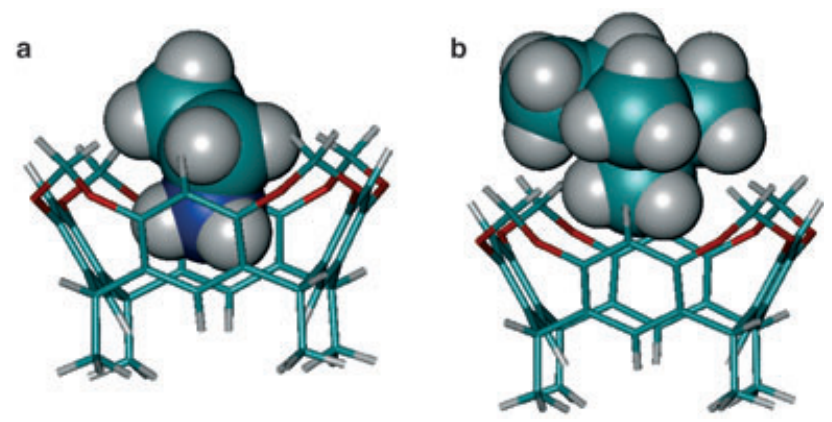

Figure 1. Gas-phase structure for the complex formed by the cavitand with a) an ethyl ammonium ion and b) an ethyl trimethyl ammonium ion. Structure optimized at the B3LPY/3-21G* level.

To investigate these interactions we applied single-molecule force spectroscopy, a method which uses the deflection of an AFM cantilever to measure minute forces in the picoNewton ( $\mathrm{pN}$ ) range under physiological conditions. In combination with its sub-nanometer spatial resolution, single-molecule force spectroscopy provides, in contrast to standard ensemble experiments, a potent tool to address and manipulate single molecules and investigate forces within and between individual molecules, to yield information about the molecular energy landscape. During the last fifteen years, AFM spectroscopy and related single-molecule techniques based on ultra-sensitive force probes have found applications in the study of molecular recognition and of the specific bond formation in a variety of systems, such as biotin-streptavidin/ avidin, ${ }^{[10,11]}$ antibody-antigen, ${ }^{[12-15]}$ selectin-ligand, ${ }^{[16]}$ DNAprotein, ${ }^{[17]}$ between individual strands of DNA, ${ }^{[18,19]}$ and celladhesion proteoglycans. $^{[20]}$

Similarly, host-guest interactions in supramolecular systems have been investigated on $\beta$-cyclodextrin-ferrocene ${ }^{[21-23]}$ and [18]crown-6-ammonium systems. ${ }^{[24,25]}$ In both cases single-molecule host-guest interaction could only be identified by a statistical analysis of the measured force distribution histograms, however, with no evidence of a loading-ratedependent force spectrum, which could account for a thermally driven unbinding and give access to the energy landscape of this interaction. In contrast to these experiments, we used diluted cavitand monolayers on a gold surface in a 1:40 mixture with didecylsulfide. The guest ions (ammonium, trimethyl ammonium, and triethyl ammonium, each carrying one additional functional group) were covalently attached to the AFM tip with a flexible poly(ethylene glycol) (PEG) linker (Figure 2). This method introduces more steric flexi-

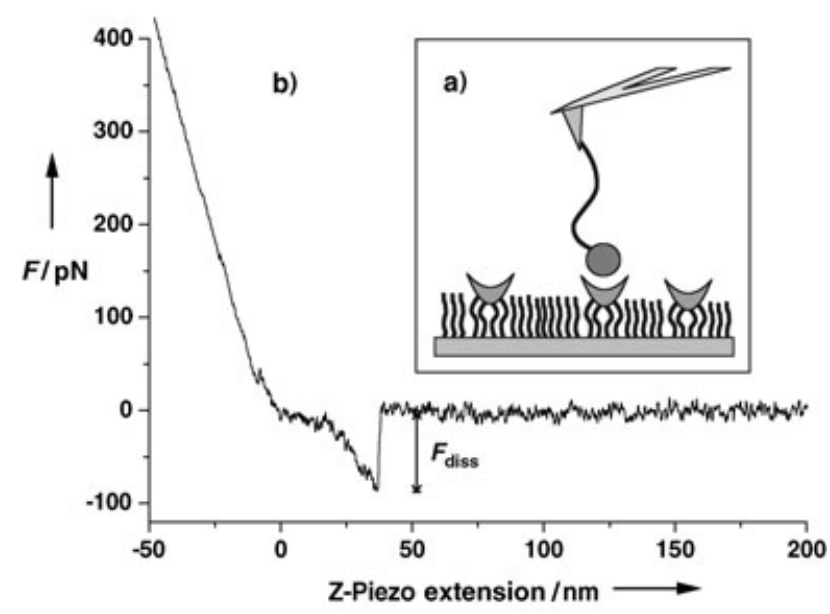

Figure 2. Force spectroscopy: a) schematic setup. The cavitand is immobilized together with didecylsulfide in a 1:40 mixture on a gold substrate. The (tetraorganyl) ammonium residue (shaded circle), is attached to an $\mathrm{Si}_{3} \mathrm{~N}_{4}$ AFM tip by a flexible polymer linker. b) Typical force-distance curve (only retractive trace shown). The stretching of the PEG linker over a certain distance prior to bond rupture (tip detachment and relaxation of the cantilever) indicates an unbinding event.

bility which facilitates complex formation and supports binding of a single host-guest pair and its proper identification. The functionalized AFM tip was repetitively approached to and retracted from the cavitand surface (in ethanol) at an adjustable but constant velocity.

Molecular unbinding events could be identified by plotting the force response of the AFM cantilever against the zposition of the piezo actuator (of the cavitand surface; Figure 2). The elastic stretching of the PEG spacer before the point of detachment, which shows an elasticity curve in accordance with the wormlike-chain polymer-elasticity model, served as the criterion to discriminate real singlebinding events from unspecific adhesion. Since the molecular unbinding process is of stochastic nature, rupture forces from many rupture events (typically 200) were compiled in a force histogram. The mean value resulting from a single-nodal Gaussian fit to the histogram distribution is the most probable unbinding force. The experimental error is based on the statistical error (standard variation) and the uncertainty in the effective spring constant of the cantilever; the errors given 
below for the thermal dissociation (off rate) at zero force and the width of the binding pocket are derived from these values by error propagation.

Figure 3 shows three force histograms for the binding of the cavitand to ammonium, trimethyl ammonium, and rupture force was comparable. Moreover, changing the solvent to ethanol saturated with competitor ion did not lead to a significant reduction of the total unbinding probability (Figure $3 \mathrm{~h}$ ), and also washing with pure ethanol again did not lead to a change (Figure $3 \mathrm{i}$ ). These findings correlate with the fact that the triethyl ammonium residue, which has a calculated diameter of $0.8 \mathrm{~nm}$, clearly exceeds the receptor cavity diameter of the resorc[4]arene cavitand: Our single-molecule experiments strongly indicate the specific and selective nature of this hostguest interaction.

According to the thermally driven unbinding theory of an activated decay of a metastable bound state ${ }^{[26,27]}$ the measured forces are not constant and depend on the temporal force evolution on the molecular complex, which is referred to as the loading rate, and can be calculated from the experimental velocity multiplied by the molecular elasticity. The elasticity of the molecular system was obtained from the slope of the force-distance curves (corrected for molecular extension) for the last 20 data points prior to detachment of the cantilever. The loading rate then was given by the system elasticity multiplied by the retract velocity.

With dynamic force spectroscopy (forceloading-rate plots) details about the kinetics of the binding and information concerning the length scale of the interaction can be extracted. The results for the natural thermal off-rates are presented in Figure 4, yielding $k_{\text {off }}=(0.99 \pm$ $0.81) \mathrm{s}^{-1}$ for the ammonium and $k_{\text {off }}=(1.87 \pm$ $0.75) \times 10^{-2} \mathrm{~s}^{-1}$ for the trimethyl ammonium residue, resulting in a bond lifetime of $\tau=1.01 \mathrm{~s}$ (for the ammonium residue) and $\tau=53.5 \mathrm{~s}$ (trimethyl ammonium residue). This finding,

triethyl ammonium residues and the corresponding competition experiments. The total unbinding probability (that is, the total number of identified rupture events divided by the number of approach-retract cycles) for the ammonium and trimethyl ammonium residues both amount to approximately $25 \%$. As a control experiment for validating the specificity of the host-guest interaction, free ammonium or tetramethyl ammonium ions were added to the solvent as competing ligands. In both cases the total (integrated) unbinding probability was significantly reduced. The effect was stronger for solvent saturated with the tetramethyl ammonium ion (Figure $3 b, e$ ). After washing tip and sample again with the original solvent (ethanol without competitor), the systems could be reactivated to their full former unbinding functionality (Figure $3 \mathrm{c}, \mathrm{f}$ ). This effect of the free ions competing with the modified ions linked to the AFM tip demonstrates the specificity of the molecular recognition between the host and guest.

For the triethyl ammonium residue, the results are different. From Figure 3, it can be seen that the integrated unbinding probability is much lower for this system than for the ammonium or tetramethyl ammonium ions, whereas the together with the results of the competition experiments, indicate that the trimethyl ammonium residue fits more

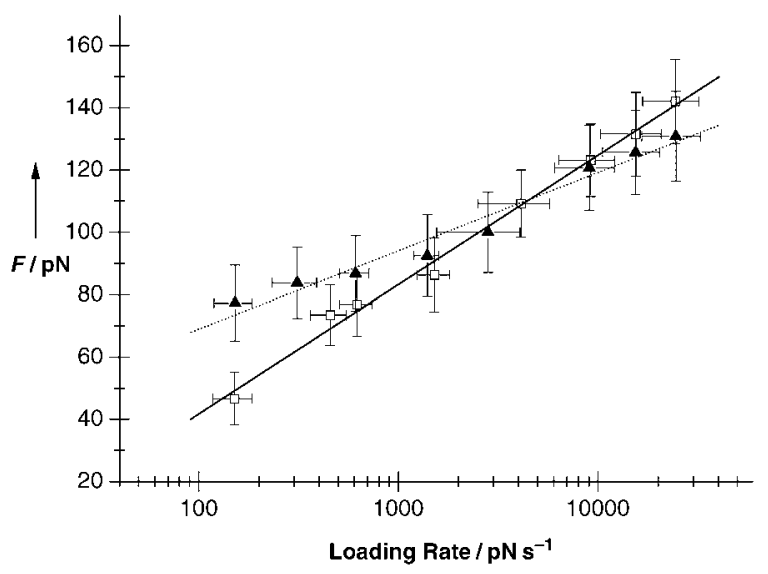

Figure 4. The unbinding forces, plotted logarithmically against the corresponding loading rates, for the binding of the ammonium ( $\square$ ) and trimethyl ammonium $(\mathbf{\Delta})$ residues to the resorc[4]arene cavitand. For details see text. 
tightly into the receptor cavity, that is, its complexation is accompanied by a greater rise in binding affinity than for ammonium. In receptor-ligand interactions, the interaction affinity (equilibrium constant of dissociation $K_{\text {diss }}=k_{\text {off }} / k_{\text {on }}$ ) is mostly dominated (and varied) by the reaction off-rate $k_{\text {off }}$, whereas the values for the reaction on-rate $k_{\text {on }}$ do not exhibit such a drastic variation. ${ }^{[13]}$ Assuming a diffusion-limited association with a typical on-rate for a ligand binding to a receptor pocket of $k_{\text {on }}=10^{5} \mathrm{M}^{-1} \mathrm{~s}^{-1},{ }^{[13,28]}$ we can deduce equilibrium constants of $K_{\text {diss }}=0.99 \mathrm{~s}^{-1} / 10^{5} \mathrm{M}^{-1} \mathrm{~s}^{-1} \approx 10^{-5} \mathrm{M}$ for ammonium ions and $K_{\text {diss }}=2 \times 10^{-2} \mathrm{~s}^{-1} / 10^{5} \mathrm{M}^{-1} \mathrm{~s}^{-1}=2 \times$ $10^{-7} \mathrm{M}$ for trimethyl ammonium ions. From the equilibrium constants for these host-guest systems the Gibbs' free energy difference $\Delta G=R T \ln K_{\text {diss }}$ can be derived, which gives a rough estimate of the related binding energies of $\Delta G \approx$ $-28 \mathrm{~kJ} \mathrm{~mol}^{-1}$ (ammonium) and $\Delta G \approx-38 \mathrm{~kJ} \mathrm{~mol}^{-1}$ (trimethyl ammonium). These values for $\Delta G$ correspond well with calorimetric or NMR spectroscopic data obtained for related supramolecular systems, such as cyclodextrins ${ }^{[23,29]}$ and watersoluble cavitands. ${ }^{[30]}$ This aspect is important for two reasons: 1) it shows that AFM force spectroscopy can be used to investigate single-molecule affinity interactions in a broad affinity range of ten orders of magnitude $\left(10^{-15} \mathrm{M}\right.$ (biotinstreptavidin) to $10^{-5} \mathrm{M}$ (this work)), and 2) that this technique allows the estimation of equilibration constants and related binding energies of single (supra)molecular complexes. This factor is of broad interest, since a determination of reaction equilibrium constants and associated binding energies of ionic binding partners with a wide variation in solubility, for example, by NMR spectroscopic titration experiments, is extremely difficult to accomplish, and no corresponding values for our system are known to us.

From the inverse slope of the loading-rate dependency the molecular reaction lengths (width of binding pocket) can be extracted yielding $x_{\beta}=(0.22 \pm 0.04) \mathrm{nm}$ for ammonium, and $x_{\beta}=(0.38 \pm 0.06) \mathrm{nm}$ for the trimethyl ammonium ions. These values are qualitatively comparable with calculated van der Waals diameters of $0.3 \mathrm{~nm}$ for ammonium and $0.6 \mathrm{~nm}$ for trimethyl ammonium. ${ }^{[9]}$ Therefore we can conclude that the steric complementarity of the host and guest plays an important role in the interaction, with cation $-\pi$ interactions contributing considerably to the molecular binding mechanism. This finding is also consistent for the interaction of the trimethyl ammonium residue with the cavitand because a the positive-charge distribution has been shown to reside on the hydrogen atoms of the methyl groups. ${ }^{[31,31]}$

In summary, we could show that the specific interaction and dissociation of single guest molecules and their host receptors in supramolecular systems are consistent with an activated decay of a metastable bound state and obey the laws of thermally driven unbinding, as predicted theoretically and verified in biological ligand-receptor systems. The measured reaction lengths were compatible with the calculated van der Waals diameters of the corresponding guest ligands, and give a rough estimate of how deep a ligand enters the receptor site of a calixarene cavitand. The measured single-molecule kinetic reaction rates are consistent with the expected nature of a moderate-affinity host-guest interaction, whereas a clear affinity ranking between the probed host ligands by single-molecule force spectroscopy was possible for the first time.

Received: July 21, 2004

Keywords: atomic force microscopy · calixarenes · host-guest systems · single molecules · supramolecular chemistry

[1] a) J.-M. Lehn, Supramolecular Chemistry, VCH, Weinheim, 1995; b) F. Vögtle, Supramolecular Chemistry, Wiley, Chichester, 1991; c) J. L. Atwood, J. E. D. Davies, D. D. Macnicol, F. Vögtle, J.-M. Lehn, Comprehensive Supramolecular Chemistry, Pergamon, New York, 1996; d) J. W. Steed, J. L. Atwood, Supramolecular Chemistry, Wiley, Chichester, 2000; e) E. Fischer, Ber. Dtsch. Chem. Ges. 1894, 27, 2985-2993; f) P. Ehrlich, Klin. Jahrb. 1897, 6, 299-326; g) A. Werner, Ber. Dtsch. Chem. Ges. 1907, 40, 15-69.

[2] C. D. Gutsche, Calixarenes, Royal Society of Chemistry, Cambridge, 1989.

[3] C. D. Gutsche, Calixarenes Revisited, Royal Society of Chemistry, Cambridge, 1998.

[4] J. Vicens, V. Böhmer, Calixarenes. A Versatile Class of Macrocyclic Compounds, Kluwer, Dordrecht, 1991.

[5] L. Mandolini, R. Ungaro, Calixarenes in Action, Imperial College Press, London, 2000.

[6] V. Böhmer, Angew. Chem. 1995, 107, 785-818; Angew. Chem. Int. Ed. Engl. 1995, 34, 713-745.

[7] P. Timmerman, W. Verboom, D. N. Reinhoudt, Tetrahedron 1996, 52, 2663-2704.

[8] D. J. Cram, S. Karbach, H. E. Kim, C. B. Knobler, E. F. Maverick, J. L. Ericson, R. C. Helgeson, J. Am. Chem. Soc. 1988, 110, 2229-2237.

[9] A. B. Rozhenko, W. W. Schoeller, M. C. Letzel, B. Decker, C. Agena, J. Mattay, unpublished results.

[10] G. U. Lee, D. A. Kidwell, R. J. Colton, Langmuir 1994, 10, $354-$ 357.

[11] E.-L. Florin, V. T. Moy, H. E. Gaub, Science 1994, 264, 415 - 417.

[12] P. Hinterdorfer, W. Baumgartner, H. Gruber, K. Schilcher, H. Schindler, Proc. Natl. Acad. Sci. USA 1996, 93, 3477-3481.

[13] F. Schwesinger, R. Ros, T. Strunz, D. Anselmetti, H.-J. Güntherodt, A. Honegger, L. Jermutus, L. Tiefenauer, A. Plückthun, Proc. Natl. Acad. Sci. USA 2000, 97, 9972-9977.

[14] U. Dammer, M. Hegner, D. Anselmetti, P. Wagner, M. Dreier, W. Huber, H.-J. Güntherodt, Biophys. J. 1996, 70, 2437-2441.

[15] R. Ros, F. Schwesinger, D. Anselmetti, M. Kubon, R. Schäfer, A. Plückthun, L. Tiefenauer, Proc. Natl. Acad. Sci. USA 1998, 95, $7402-7405$

[16] J. Fritz, A. G. Katopodis, F. Kolbinger, D. Anselmetti, Proc. Natl. Acad. Sci. USA 1998, 95, 12283-12288.

[17] F. W. Bartels, B. Baumgarth, D. Anselmetti, R. Ros, A. Becker, J. Struct. Biol. 2003, 143, 145-152.

[18] G. U. Lee, L. A. Chrisey, R. J. Colton, Science 1994, 266, 771773.

[19] T. Strunz, K. Oroszlan, R. Schäfer, H.-J. Güntherodt, Proc. Natl. Acad. Sci. USA 1999, 96, 11277-11282.

[20] U. Dammer, O. Popescu, P. Wagner, D. Anselmetti, H.-J. Güntherodt, G. N. Misevic, Science 1995, 267, 1173-1175.

[21] H. Schönherr, M. W. J. Beulen, J. Bügler, J. Huskens, F. C. J. M. van Veggel, D. N. Reinhoudt, G. J. Vancso, J. Am. Chem. Soc. 2000, 122, 4963-4967.

[22] S. Zapotoczny, T. Auletta, M. R. de Jong, H. Schönherr, J. Huskens, F. C. J. M. van Veggel, D. N. Reinhoudt, G. J. Vancso, Langmuir 2002, 18, 6988-6994.

[23] T. Auletta, M. R. de Jong, A. Mulder, F. C. J. M. van Veggel, J. Huskens, D. N. Reinhoudt, S. Zou, S. Zapotoczny, H. Schönherr, 
G. J. Vancso, L. Kuipers, J. Am. Chem. Soc. 2004, 126, $1577-$ 1584.

[24] S. Kado, K. Kimura, J. Am. Chem. Soc. 2003, 125, 4560-4564.

[25] S. Kado, K. Yamada, K. Kimura, Langmuir 2004, 20, 3259-3263.

[26] G. I. Bell, Science 1978, 200, 618-627.

[27] E. Evans, K. Ritchie, Biophys. J. 1997, 72, 1541-1555.

[28] M. Schlosshauer, D. Baker, Protein Sci. 2004, 13, 1660-1669.
[29] L. A. Godínez, L. Schwartz, C. M. Criss, A. E. Kaifer, J. Phys. Chem. B 1997, 101, 3376-3380.

[30] T. Haino, D. M. Rudkevich, A. Shivanyuk, K. Rissanen, J. Rebek, Jr., Chem. Eur. J. 2000, 6, 3797-3805.

[31] C. A. Deakyne, M. Meot-Ner (Mautner), J. Am. Chem. Soc. 1985, 107, 474-479.

[32] H. J. Schneider, T. Schiestel, P. Zimmermann, J. Am. Chem. Soc. 1992, 114, $7698-7703$. 